Пожарская Т.P.

К ВОПРОСУ О НОРМАТИВНЫХ ОСНОВАХ

РЕАЛИЗАЦИИ ОРТАНАМИ МЕСТНОГО

САМОУПРАВЛЕНИЯ КОНСТИТУЦИОННОГО

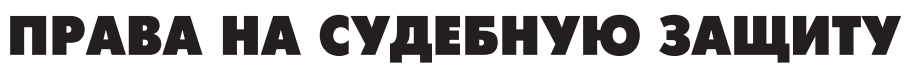

В ГРАХДАНСКОМ И АРБИТРАКНОМ IPOHECCAX

Pozharskaya T. R.

\title{
ON THE ISSUE OF THE REGULATORY FRAMEWORK FOR THE IMPLEMENTATION BY LOCAL SELF- GOVERNMENT BODIES OF THE CONSTITUTIONAL RIGHT TO JUDICIAL PROTECTION IN CIVIL AND ARBITRATION PROCEEDINGS
}

В настоящее время федеральное законодательство, регламентирующее вопросы правовой, территориальной и экономической организации местного самоуправления в Российской Федерации, основывается на закрепленном в Конституции Российской Федерации принципе признания, соблюдения и защиты прав и свобод человека и гражданина. Поэтому нельзя исключать органы местного самоуправления из числа субъектов, реализующих право на судебную защиту прав, свобод и законных интересов других лиц, поскольку одним их приоритетных направлений их деятельности является защита прав и интересов населения муниципального образования.

Ключевые слова: право на судебную защиту, компетенция, гражданское судопроизводство, полномочия, арбитражное судопроизводство, органы местного самоуправления

Currently, the federal legislation regulating the legal, territorial and economic organization of local self-government in the Russian Federation is based on the principle of recognition, observance and protection of human and civil rights and freedoms enshrined in the Constitution of the Russian Federation. Therefore, it is impossible to exclude local self-government bodies from the number of subjects exercising the right to judicial protection of the rights, freedoms and legitimate interests of other persons, since one of their priority areas of their activity is the protection of the rights and interests of the population of the municipality.

Keywords: right to judicial protection, competence, civil proceedings, powers, arbitration proceedings, local self-government bodies

Уровень обеспечения прав и свобод человека и гражданина в правовом государстве является комплексным критерием оценки степени экономической, политической, социальной и правовой стабильности государства, а также развития общества и личности в целом. Признавая права и свободы человека высшей ценностью, ст. 2 Конституции Российской Фе- дерации возложила на государство обязанность по их признанию, соблюдению и защите.

Закрепление в ст. 46 Конституции Российской Федерации права на судебную защиту послужило основой для формирования и развития отраслевого законодательства, призванного конкретизировать указанные конституционные положения и 
порядок их реализации, поскольку как неоднократно отмечал Конституционный Суд Российской Федерации, исходя из предписаний ч. 2 ст. 45 и ч. 1 ст. $46 \mathrm{Koн-}$ ституции Российской Федерации, заинтересованное лицо по своему усмотрению выбирает формы и способы защиты своих прав, не запрещенные законом, в том числе посредством обращения за судебной защитой, будучи связанным лишь установленным федеральным законом порядком судопроизводства ${ }^{1}$. Иными словами, право на судебную защиту неразрывно связано с процессуальной формой его реализации и установленных законом правил судопроизводства.

Право на судебную защиту в традиционной форме его осуществления реализуется гражданами и юридическими лицами, а также их представителями путем обращения в судебные инстанции в целях защиты собственных нарушенных прав. Однако в ряде случаев, когда само общество нуждается в защите прав, свобод и законных интересов, указанное право может быть реализовано органами власти и органами местного самоуправления в порядке ст. 46 ГПК РФ и ст. 53 АПК РФ.

Положения ст. ст. 18, 132, 133 Конституции Российской Федерации позволяют выделить органы местного самоуправления в качестве субъектов, уполномоченных защищать конституционные права и свободы личности. При этом, муниципальные образования являются весьма специфичным субъектом конституционно-правовых споров, поскольку, являясь публичными образованиями, наделены властью, обладающей единой природой с государственной властью, реализуют публичные функции государства при решении вопросов местного значения, а само местное самоуправление представляет собой неотъемлемую часть единого механизма управления делами государства ${ }^{2}$. В этой связи следует согласиться с

1 Определение Конституционного Суда РФ от 28.05.2013 № 750-О «Об отказе в принятии к рассмотрению жалобы гражданина Дмитриева Сергея Александровича на нарушение его конституционных прав статьями 39 и 45 Гражданского процессуального кодекса Россий-ской Федерации» // URL: http://www.consultant.ru (дата обращения: 20.09.2020)

2 Постановление Конституционного Суда Российской Федерации от 26.04.2016 № 13-П «По делу о проверке конституционности пункта 18 части 1 статьи 14 и пункта 14 части 1 статьи 15 Федерального закона «Об общих принципах организации местного самоуправления в Российской Федерации" в связи с жалобой администрации муниципального образования «Нерюнгринский район» // Собрание законодательства Российской Федерации. 2016. № 19. Ст. 2774. мнением Н.С. Бондаря, полагающего, что местное самоуправление и его органы представляют особый негосударственный уровень единой конституционной системы обеспечения и защиты основных прав и свобод человека и гражданина в Российской Федерации [1, с. 52-53].

Как было отмечено выше, положения ст. 46 ГПК РФ допускают участие органов местного самоуправления в гражданском процессе в качестве субъекта, выступающего в защиту прав, свобод и законных интересов других лиц по их просьбе либо в защиту прав, свобод и законных интересов неопределенного круга лиц. В то время как в силу ст. 53 АПК РФ органы местного самоуправления могут обратиться в арбитражный суд как инициаторы возбуждения дела в защиту публичных интересов либо возбуждения дела в защиту прав и законных интересов других лиц.

Такие обращения органов местного самоуправления за судебной защитой в подобных случаях направлены на обеспечение соблюдения Конституции Российской Федерации и исполнение законов, действующих на территории РФ, охрану прав и свобод неопределенного круга лиц, публичных интересов, а также прав, свобод и законных интересов других лиц, являющихся по совокупности несомненным приоритетом в рамках правового государства, которая может быть достигнута только в случае вынесения законного и обоснованного решения суда.

Нельзя не отметить тот факт, что положения Федерального закона «Об общих принципах организации местного самоуправления в Российской Федерации» не содержат конкретного перечня случаев, когда органами местного самоуправления может быть реализовано право на судебную защиту прав, свобод и законных интересов других лиц.

Решение вопросов, находящихся в рамках предмета ведения муниципальных образований, обусловливает определенную компетенцию их органов и выступает главным юридическим средством, с помощью которого органы местного самоуправления выполняют свои функции на соответствующей территории.

Одним из основных элементов структуры компетенции местного самоуправления выступают полномочия органов местного самоуправления, с помощью которых реализуется публично-властный характер функций и задач местного самоуправления. Согласно справедливому уточнению С.А. Авакьяна, полномочия определяются как права и обязанности государственного органа, органа местно-

\section{3}


го самоуправления, должностного лица, иных участников общественных отношений, установленные нормативным юридическим актом [4, с. 429]. По мнению О.Е. Кутафина и Е.И. Козловой, полномочия местного самоуправления включают права и обязанности муниципальных образований в целом. Соответственно, полномочия в первую очередь соотносятся с деятельностью органов местного самоуправления и должностных лиц [3, с. 367] С позиции И.В. Выдрина, полномочия (права и обязанности) муниципальных органов означают принадлежащие им права на совершение определенного вида властных действий. Для публичной сферы это еще и обязанность муниципальной власти [2, с. 185].

Среди полномочий органов местного самоуправления можно выделить четыре основных группы:

- собственные полномочия, установленные Федеральным законом «Об общих принципах организации местного самоуправления в Российской Федерации» и уставами муниципальных образований;

- отдельные государственные полномочия, передаваемые федеральными законами и законами субъектов Российской Федерации;

- дополнительные полномочия - осуществление иных государственных полномочий, В случаях, предусмотренных федеральными законами;

- добровольно принимаемые полномочия - реализация полномочий по иным вопросам, не отнесенным к компетенции органов местного самоуправления других муниципальных образований, органов государственной власти и не исключенных из их компетенции федеральными законами и законами субъектов Российской Федерации.

Рассматривая полномочия как совокупность прав и обязанностей органов местного самоуправления по решению вопросов, относящихся к предмету ведения муниципальных образований, необходимо учитывать, что обращения указанных субъектов права в гражданском и арбитражном судопроизводстве в порядке ст. 46 ГПК РФ и ст. 53 АПК РФ возможны в случаях, предусмотренных законом.

В то же время приведенный в нашем исследовании подробный анализ законодательства, закрепляющего за органами местного самоуправления полномочия по решению вопросов, относящихся к предмету ведения муниципальных образований, позволяет прийти к выводу о наличии неясности в определении нормативного акта, закрепляющего право обращения органов местного самоуправления за судебной защитой прав, свобод и законных интересов других лиц, и детерминации субъекта из числа органов, входящих в структуру органов местного самоуправления, уполномоченного на обращение в суд в порядке ст. 46 ГПК РФ и ст. 53 АПК РФ от имени муниципального образования в интересах неопределенного круга лиц, публичных интересов, интересов других лиц.

Иными словами, в правоприменительной деятельности мы сталкиваемся с ситуацией, когда процессуальными кодифицированными актами норма, предоставляющая возможность инициирования спора, определена, но не может быть реализована по причине отсутствия закона или иного нормативного правового акта, предоставляющего данное правомочие, к которому она отсылает, что свидетельствует о дефекте конструкции правовых норм, затрудняющим их осуществление вследствие нарушения функциональных связей с другими элементами системы права, процедур и механизма их реализации, влекущих неисполнение или ненадлежащее исполнение юридических обязанностей субъектами права.

В соответствии со ст. 17 Федерального закона «Об общих принципах организации местного самоуправления в Российской Федерации» органы местного самоуправления обладают собственными полномочиями для решения вопросов местного значения (ст. ст. 14-16 Федерального закона «Об общих принципах организации местного самоуправления в Российской Федерации»). Такие полномочия устанавливаются Федеральным законом «Об общих принципах организации местного самоуправления в Российской Федерации», уставами муниципальных образовании, а также актами отраслевого законодательства.

Однако ни один нормативный правовой акт из вышеперечисленных не закрепляет за органами местного самоуправления права на инициирование спора в гражданском и арбитражном судопроизводстве в защиту интересов иных лиц.

Органы местного самоуправления обладают не только собственными полномочиями по решению вопросов местного значения, но также выполняют отдельные государственные полномочия, передаваемые федеральными законами и законами субъектов Российской Федерации.

Согласно ч. 1 ст. 19 Федерального закона «Об общих принципах организации местного самоуправления в Российской Федерации» полномочия органов мест- 
ного самоуправления, установленные федеральными законами и законами субъектов Российской Федерации, по вопросам, не отнесенным Федеральным законом «Об общих принципах организации местного самоуправления в Российской Федерации» к вопросам местного значения, являются отдельными государственными полномочиями.

Из анализа положений ч. 2 ст. $132 \mathrm{Koн}-$ ституции Российской Федерации и ч. 2 ст. 19 Федерального закона «Об общих принципах организации местного самоуправления в Российской Федерации» следует, что государственные полномочия могут передаваться органам местного самоуправления только законами:

- федеральными - полномочия Российской Федерации по предметам ведения Российской Федерации и по предметам совместного ведения Российской Федерации и субъектов Российской Федерации;

- субъектов Российской Федерации полномочия субъектов Российской Федерации по предметам ведения субъектов Российской Федерации, по предметам совместного ведения Российской Федерации и субъектов Российской Федерации, а также в случаях, предусмотренных федеральными законами - полномочия Российской Федерации, переданные для осуществления субъектам Российской Федерации

В развитие указанных положений Конституционный Суд Российской Федерации в Постановлении от 30.11.2000 № 15-П подчеркнул, что наделение органов местного самоуправления отдельными государственными полномочиями может осуществляться только законодателем федеральным или субъекта Российской Федерации и только в форме закона с учетом установленных Конституцией Российской Федерации предметов ведения и полномочий Российской Федерации и субъектов Российской Федерации ${ }^{3}$.

К числу некоторых федеральных полномочий, делегированных в настоящее время органам местного самоуправления, можно отнести первичный воинский учет в местностях, где нет военкоматов (п. 2 ст. 8 Федерального закона «О воинской обязанности и военной службе»). Среди

3 Постановление Конституционного Суда РФ от 30.11.2000 № 15-П «По делу о проверке конституционности отдельных положений Устава (Основного Закона) Курской области в редакции Закона Курской области от 22 марта 1999 года «О внесении изменений и допол-нений в Устав (Основной Закон) Курской области» // Вестник Конституционного Суда РФ. № 1. 2001. собственных полномочий субъектов Российской Федерации по предметам совместного ведения на местный уровень могут передаваться такие полномочия как, например, формирование и содержание архивных фондов субъекта Российской Федерации (ч. 2 ст. 20 Закона Свердловской области от 25.03.2005 № 5-О3 «Об архивном деле в Свердловской области»). Также органы местного самоуправления могут наделяться полномочиями из числа делегированных субъектам Российской Федерации федеральных полномочий по государственной регистрации актов гражданского состояния (абз. 4 п. 1 ст. 4 Федерального закона «Об актах гражданского состояния»).

Вместе с тем, ни федеральные законы, ни законы субъектов Российской Федерации, наделяющие органы местного самоуправления государственными полномочиями, не закрепляют за ними право на обращение за судебной защитой в интересах неопределенного круга лиц, публичных интересов, интересов других лиц.

Положения Федерального закона «Об общих принципах организации местного самоуправления в Российской Федерации» также предусматривают возможность закрепления за органами местного самоуправления дополнительных полномочий в виде осуществления иных государственных полномочий (не переданных им в соответствии со ст. 19 Федерального закона «Об общих принципах организации местного самоуправления в Российской Федерации»), в случаях, предусмотренных федеральными законами.

При этом, как отмечает А.В. Мадьярова, нередко выяснение истинной природы тех или иных полномочий, закрепленных за органами местного самоуправления иными федеральными законами, весьма затруднительно, требует детального глубокого анализа в каждом конкретном случае и даже при этом условии не всегда приводит к бесспорным результатам [5].

Анализ федеральных законов, наделяющих органы местного самоуправления иными государственными полномочиями (не переданными им в соответствии со ст. 19 Федерального закона «Об общих принципах организации местного самоуправления в Российской Федерации»), свидетельствует о том, что не все нормативноправовые акты закрепляют право органов местного самоуправления по обращению в суд в интересах неопределенного круга лиц, публичных интересов, интересов других лиц.
45 
Так, в частности, положениями п. 4 ч. 1 ст. 14, п. 4 ч. 1 ст. 16, п. 4 ч. 1 ст. 17 Федерального закона «Об общих принципах организации местного самоуправления в Российской Федерации» к вопросам местного значения отнесен вопрос по организации органами местного самоуправления теплоснабжения в пределах полномочий, предусмотренных Федеральным законом «О теплоснабжении».

Полномочия органов местного самоуправления в сфере теплоснабжения детально регламентированы в ст. 6 Федерального закона от 27.07.2010 № 190-ФЗ «О теплоснабжении», среди которых не установлено право обращения в суд в защиту прав, свобод и законных интересов других лиц.

Другим примером может послужить реализация правомочий органов местного самоуправления по осуществлению мероприятий по защите прав потребителей, предусмотренных Законом Российской Федерации от 07.02.1992 № 2300-1 «О защите прав потребителей», не отнесенных к вопросам местного значения в силу п. 17 ч. 1 ст. 14.1 , п. 16 ч. 1 ст. 15.1 , п. 18 ч. 1 и п. 6 ч. 1.1 ст. 16.1 Федерального закона «Об общих принципах организации местного самоуправления в Российской Федерации».

Однако положения ст. 44 Законом Российской Федерации от 07.02.1992 № 2300-1 «О защите прав потребителей», регулирующие вопросы осуществления защиты прав потребителей органами местного самоуправления, закрепляют за указанными субъектами право обращаться в суды в защиту прав потребителей (неопределенного круга потребителей).

Нельзя не отметить еще одну группу полномочий, осуществляемых органами местного самоуправления. Это собственно добровольно принимаемые полномочия, реализуемые по решению иных вопросов, не отнесенных к компетенции органов местного самоуправления других муниципальных образований, органов государственной власти и не исключенных из их компетенции федеральными законами и законами субъектов Российской Федерации. Как справедливо отмечено С.Б. Нанбой, данные вопросы, если они приняты к исполнению на уровне муниципального образования, могут быть на период, пока они не изъяты из ведения муниципального образования и не переданы в ведение другого субъекта права (Федерации или ее субъектов, других муниципальных образований), отнесены к ведению данного муниципального образования [6, с. 44-49].
Иными словами, так называемые добровольно принимаемые полномочия осуществляются органами местного самоуправления на добровольной основе и закрепляются уставом муниципального образования.

Таким образом, в вопросе реализации органами местного самоуправления права на судебную защиту возникает проблема недостаточной нормативно-правовой регламентации определения границ и закрепления права по обращению этих субъектов в гражданском и арбитражном процессах в порядке ст. 46 ГПК РФ и ст. 53 АПК РФ. Подобный пробел в праве является неопределенностью закона в части установления оснований обращения органов местного самоуправления за судебной защитой прав, свобод и законных интересов других лиц.

При этом необходимость соблюдения принципа правовой определенности подчеркивалась не только Конституционным Судом Российской Федерации, как свойства согласованности правовых норм в системе общего правового регулирования ${ }^{4}$, но и Европейским судом по правам человека при применении содержащихся или вытекающих из Конвенции о защите прав человека и основных свобод общих принципов, лежащих, в том числе в основе оценки соответствия ее положениям внутригосударственного права ${ }^{5}$.

Справедливым в этой части представляется мнение Г.А. Гаджиева, согласно которому в настоящее время требование (принцип) правовой определенности признан Конституционным Судом Российской Федерации универсальным и обще-

${ }^{4}$ Определение Конституционного Суда Российской Федерации от 10.07.2003 № 270-О «Об отказе в принятии к рассмотрению запроса Курганского городского суда Курганской обла-сти о проверке конституционности части первой статьи 3, статьи 10 Уголовного кодекса Российской Федерации и пункта 13 статьи 397 Уголовно-процессуального кодекса Россий-ской Федерации» // Вестник Конституционного Суда РФ. № 5. 2003. 5 Постановления ЕСПЧ от 26.04.1979 по делу «Санди Таймс» (Sunday Times) против Соединенного Королевства (№ 1)» // URL: http://www. consultant.ru (дата обращения: 01.09.2021); Постановления ЕСПЧ от 31.07.2000 по делу «Иечиус (Jecius) против Литвы»; от 28.03.2000 по делу "Барановский (Baranowski) против Польши" // URL: http://www.consultant.ru (дата обращения: 01.09.2021); Постановления ЕСПЧ от 28.10.2003 по делу «Ракевич против Рос-сийской Федерации» // URL: http://www.consultant.ru (дата обращения: 01.09.2021); Поста-новления ЕСПЧ от 24.05.2007 по делу «Игнатов против Российской Федерации» // URL: http://www.consultant.ru (дата обращения: 01.09.2021); Постановления ЕСПч от 24.05.2007 по делу «Владимир Соловьев против Российской Федерации" // URL: http://www. consultant.ru (дата обращения: 01.09.2021). 
обязательным, относящимся к основам конституционного строя [7, с. 37].

В целях преодоления элементов правовой неопределенности в вопросе определения оснований обращения органов местного самоуправления в суд в интересах иных лиц в гражданском и арбитражном судопроизводстве, учитывая особую значимость реализации указанными субъектами права на судебную защиту, нами предлагается внесение корректировок в правовую конструкцию реализации органами местного самоуправления права на судебную защиту при осуществлении ими:

- собственных полномочий - внести дополнения в ч. 1 ст. 17 Федерального закона «Об общих принципах организации местного самоуправления в Российской Федерации» в части указания права органов местного самоуправления по обращению за судебной защитой прав, свобод и законных интересов других лиц, а также закрепив данное право за одним субъектов из числа органов, входящих в структуру органов местного самоуправления, в уставе муниципального образования;

- отдельных государственных полномочий - закрепить в соответствующих нормативных актах, предусматривающих наделение органов местного самоуправления отдельными государственными полномочиями, их права на обращение в суд в порядке ст. 46 ГПК РФ и ст. 53 АПК РФ;

- дополнительных полномочий - указать в соответствующих нормативных актах право на обращение в суд в порядке ст. 46 ГПК РФ и ст. 53 АПК РФ;

- добровольно принимаемых полномочий - опосредованно закрепить в качестве полномочия данное право за одним из органов, входящих в структуру органов местного самоуправления, в уставе муниципального образования

Реализация вышеуказанных предложений позволит закрепить правомочия органов местного самоуправления по осуществлению предоставленного им процессуальными кодифицированными актами Российской Федерации права на судебную защиту в порядке ст. 46 ГПК РФ и ст. 53 АПК РФ и придаст большей гибкости судебному усмотрению на предмет наличия либо отсутствия оснований для подобного рода обращений, а также позволит возвести органы местного самоуправления в ранг равноправного субъекта права наравне с органами государственной власти и государственными органами.

Предложенные изменения позволят, во-первых, законодательно регламентировать право обращения муниципального органа в арбитражные суды и суды общей юрисдикции в интересах неопределенного круга лиц, публичных интересов, интересов других лиц, что будет содействовать совершенствованию законодательства о местном самоуправлении; вовторых, повысить роль судебных гарантий по реализации органами местного самоуправления конституционного права на судебную защиту.

Таким образом, отсутствие в нормативных актах и уставах муниципальных образований четких критериев, определяющих компетенцию органов местного самоуправления, приводят к тому, что в правоприменительной деятельности возникают ситуации, когда норма, предоставляющая органам местного самоуправления возможность инициирования спора, определена, но не может быть реализована по причине отсутствия нормативного правового акта, предоставляющего данное правомочие, к которому она отсылает, что свидетельствует о дефекте правовой конструкции, влекущем неисполнение или ненадлежащее исполнение юридических обязанностей субъектами права, что негативно сказывается на эффективности механизма реализации права на обращения в суд в защиту прав, свобод и законных интересов других лиц.

\section{Литература}

1. Бондарь Н.С. Гражданин и публичная власть: конституционное обеспечение прав и свобод граждан в местном самоуправлении. М., 2004. С. 52-53.

2. Выдрин И.В. Муниципальное право России // М. 2012. С. 185.

3. Козлова Е.И., Кутафин О.Е. Конституционное право РФ // М. 2013. С. 367.

4. Конституционное право. Энциклопедический словарь / отв. ред. С.А. Авакьян // M., 2001. С. 429.

5. Мадьярова А.В. Предметы ведения муниципальных образований и полномочия органов местного самоуправления: попытка системного анализа // URL: http://www.consultant.ru (дата обращения: 01.09.2021).

6. Нанба С.Б. О «собственных» полномочиях органов местного самоуправления // Журнал российского права. 2010. № 12. С. 44 - 49.

7. Налоговая система за последние 10 лет: мнения экспертов // Налоговед. № 1. 2014. С. 37 . 


\section{References}

1. Bondar' N.S. Grazhdanin i publichnaya vlast': konstitutsionnoye obespecheniye prav i svobod grazhdan v mestnom samoupravlenii. M., 2004. S. 52-53.

2. Vydrin I.V. Munitsipal'noye pravo Rossii // M. 2012. S. 185.

3. Kozlova Ye.I., Kutafin O.Ye. Konstitutsionnoye pravo RF // M. 2013. S. 367

4. Konstitutsionnoye pravo. Entsiklopedicheskiy slovar' / otv. red. S.A. Avak'yan //

M., 2001. S. 429.

5. Mad'yarova A.V. Predmety vedeniya munitsipal'nykh obrazova-niy i polnomochiya organov mestnogo samoupravleniya: popytka sistemnogo ana-liza // URL: http:// www.consultant.ru (data obrashcheniya: 01.09.2021).

6. Nanba S.B. O «sobstvennykh» polnomochiyakh organov mestnogo samoupravleniya // Zhurnal rossiyskogo prava. 2010. № 12. S. 44 - 49.

7. Nalogovaya sistema za posledniye 10 let: mneniya ekspertov // Nalo-goved. № 1. 2014. S. 37

ПОЖАРСКАЯ Татьяна Ринатовна, аспирант кафедры конституционного права Федеральное государственное бюджетное образовательное учреждение высшего образования «Уральский государственный юридический университет». Россия, 620137, г. Екатеринбург, ул. Комсомольская, 21. E-mail: trpozharskaya@gmail.com

POZHARSKAYA Tatiana, Postgraduate student of the Department of Constitutional Law, Federal State Budgetary Educational Institution of Higher Education "Ural State Law University". Russia, 620137, Yekaterinburg, Komsomolskaya str., 21. E-mail: trpozharskaya@gmail.com 